\title{
Professional Development Needs of Non-Radiology Nurses: An Exploration of Nurses' Experiences Caring for Interventional Radiology Patients
}

\author{
Andra Carley, MN, CRN, BScN, RN ${ }^{\mathrm{a},{ }^{*}}$, Sherri Melrose, PhD, RN ${ }^{\mathrm{b}}$, Gwen Rempel, PhD, RN ${ }^{\mathrm{b}}$, \\ William Diehl-Jones, $\mathrm{PhD}^{\mathrm{b}}{ }^{\mathrm{b}}$, Betty Anne Schwarz, DProf, MSc, BA, RN ${ }^{\mathrm{c}}$ \\ a Peterborough Regional Health Centre, 1 Hospital Drive, Peterborough, ON, Canada \\ ${ }^{\mathrm{b}}$ Athabasca University, 1 University Drive, Athabasca, AB, Canada

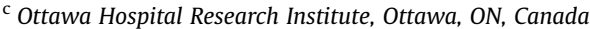

Keywords:

IR nursing

Interventional radiology education

Nonradiology nurse

\begin{abstract}
A B S T R A C T
Nursing in interventional radiology is diverse and multifaceted. This area of specialty nursing has not yet been acknowledged as such or embraced in Canada. Professional development for interventional radiology nurses is lacking with even fewer educational opportunities for non-radiology nurses who care for interventional radiology patients throughout the hospital to develop needed interventional radiology knowledge and related skills. This qualitative descriptive study explored the experiences non-radiology nurses have caring for interventional radiology patients. Interviews with ten non-radiology nurses in a Canadian hospital provided rich data for analysis. Thematic analysis revealed that these nurses did not receive formal IR education in their nursing curriculum, acquired their knowledge through self-teaching, lacked knowledge about imaging modalities and IR procedures, were impeded to build trusting nursepatient relationships, and felt ineffective communication disrupted the continuity of care they provided. Addressing professional development needs related to creating interventional radiology education, increasing awareness of the specialty of interventional radiology nursing, and enhancing clinical collaboration is a key recommendation.
\end{abstract}

() 2020 Association for Radiologic \& Imaging Nursing. Published by Elsevier Inc. All rights reserved.

\section{Introduction}

Interventional radiology (IR) is a medical specialty within radiology that differs from diagnostic radiology, in that minimally invasive procedures are performed for diagnostic, therapeutic, curative, and palliative purposes using the imaging guidance of ultrasound, fluoroscopy, and computed tomography (CT) (the Canadian Association of Interventional Radiology [CAIR], 2018). This innovative practice with the use of local and conscious sedation in IR facilities has become an alternative to traditional surgery with general anesthesia in operating rooms. The multipurpose nature of these IR procedures combined with the significant benefits of

Conflict of interest: The author(s) have no relevant disclosures. There was no grant funding or financial support for this manuscript.

* Corresponding author: Andra Carley, 23 Ridgewood Court, Peterborough, ON K9J 8A1, Canada.

E-mail address: alcarley003@sympatico.ca (A. Carley). shorter hospital stays, improved patient outcomes, and hospital cost savings has resulted in an increased demand for IR services (Foo, 2018; Zeidenberg, 2007).

The role of IR is officially recognized as a medical subspecialty of radiology in Canada, the United States, Australia, and some regions of the United Kingdom and Europe. In Canada, the CAIR is a multidisciplinary group geared to interventional radiologists, registered nurses (RNs), and medical radiation technologists (MRTs). Their mission is to help Canadians achieve optimal health and quality of life using IR procedures (CAIR, n.d.). In the United States, the Association for Radiologic and Imaging Nursing (ARIN) exists to lead, educate, promote, and advance awareness and professional development for this nursing specialty (ARIN, n.d.). In Australia, the Medical Imaging Nurses Association of Australia (MINA) promotes the nursing specialty (MINA, n.d.). However, there are no nursing organizations in Canada that do the same.

IR procedures are performed in IR suites within acute care facilities with a dedicated team of interventional radiologists, MRTs, 
and RNs. Nursing in IR is diverse and multifaceted. Nursing care for IR patients in the hospital extends beyond the IR department to the inpatient wards and is provided by nurses who do not share the same familiarity with the specialty of IR. Yet, research examining the experiences and professional development needs of the nurses providing this care, particularly those who do not have specialized IR training, is limited. The purpose of this study was to explore the learning, perceptions, and experiences of non-radiology nurses who work in hospitals caring for IR patients. In this article, we present findings from a qualitative research study that analyzed interview data to describe the experiences of ten non-radiology nurses at a Canadian hospital.

\section{Methods}

A constructivist conceptual framework guided the inquiry (Creswell \& Poth, 2018; Guba \& Lincoln, 1994; Kivunja \& Kuyini, 2017). Qualitative descriptive methodology was implemented to understand and then describe the non-radiology nurses' experiences. This methodology was well suited to detail words, events, and viewpoints using the participants' own words, which allows the researcher to remain close and even get closer to the data in the analysis process (Creswell \& Poth, 2018; Sandelowski, 2000; Lambert \& Lambert, 2012; Neergaard, Oleson, Andersen \& Sondergaard, 2009; Willis, Sullivan-Bolyai, Knafl \& Cohen, 2016; Aspers \& Corte, 2019).

\section{Sample and Setting}

This study was implemented at a 460-inpatient bed Canadian hospital. Ten nurses with varied work experience and exposure to IR patients volunteered to participate after placement of recruitment posters on inpatient wards. Each participant met the key criteria of working outside the radiology department and having had experience caring for at least one IR patient. Qualitative research supports purposeful sampling whereby researchers choose participants who will provide rich and unique information about the experiences under investigation (Bradshaw, Atkinson \& Doody, 2017; Neergaard et al., 2009; Richards \& Morse, 2013; Sandelowski, 2000).

\section{Data Collection}

Official memorandums granting ethical approval were received from both the researchers' university and the hospital, and all participants signed an informed consent form. Audio-recorded, semistructured, face-to-face interviews were conducted in quiet locations and followed the same interview guide. The first author conducted all of the interviews and opened each interview with an invitation to the following: "Tell me about your experience providing care to IR patients?" Probing questions were asked to encourage participants to broaden their response. For example, "Describe a situation when you cared for an IR patient?" This was followed by probes such as "Can you talk a bit more about that?". Using openended questions and probing subquestions during the interview invited participants to speak freely and to gain and articulate a deep, true reflection of their perspectives (Neergaard et al., 2009).

\section{Data Analysis}

Interviews were transcribed verbatim and analyzed for themes. Thematic analysis provides a description of data sets in their entirety (Braun \& Clarke, 2006) and works well with qualitative descriptive methodology, the goal of which is to achieve a rich description of the participants' experiences (Creswell \& Poth, 2018;
Lambert \& Lambert, 2012; Neergaard et al., 2009; Sandelowski, 2010). Analysis involved initial reading of the transcripts for salient aspects and re-reading the data for coding and categorizing to identify the excerpts, meanings, and themes that described the nonradiology nurses' experiences. See Table 1 for a sample of significant excerpts, meanings, and themes.

\section{Findings}

A rich description of the participant experiences resulted from a thorough analysis of the data resulting in the following five themes previously noted in Table 1: (1) no formal IR education in nursing curriculum, (2) acquired knowledge through self-teaching, (3) lacked knowledge about imaging modalities and IR procedures (4) IR knowledge gap prevented development of a trusted nurse-patient relationship, and (5) incomplete handoffs and ineffective communication disrupted continuity of care.

\section{No Formal IR Education in Nursing Curriculum}

Most participants indicated that they had no formal education or clinical opportunities to learn about IR procedures during their undergraduate nursing programs. When two nurses reflected on an IR procedure that involved the placement of a percutaneous drain, they attributed their lack of knowledge of drain care to "not learning about it in school" (participants 1 and 3).

Non-radiology nurses talked about working with many new graduate nurses who had no experience and no awareness of the IR procedures and "all the risks associated, as there has not been any education about IR procedures, so we are having to do a lot of teaching" (participant 4). This was echoed by a nurse who commented "I think the junior nurses still need to be guided on everything. They don't know you know, and all of our learning is experience based, that is just the way it is pretty much" (participant 5).

\section{Acquired Knowledge Through Self-Teaching}

There was consensus among participants that they acquired their IR knowledge through self-teaching. This was influenced by how often they cared for IR patients. "The knowledge comes from where you work... what types of patients you see would be the types of procedures. It is all experience based, I honestly feel" (participant 5). Nurses in high-turnover areas, such as the emergency department, and those who had several years of experience working with IR patients commented on how this experience helped them gain the knowledge they needed. Non-radiology nurses who lacked experience caring for IR patients deferred to the nurses who had more experience. One nurse described "relying on the assessment skills you already have and just kind of guessing what you are expecting for complications" (participant 6). They felt IR was an area that you either had exposure to or not.

\section{Lacked Knowledge About Imaging Modalities and IR Procedures}

In the present study, non-radiology nurses did not have a clear understanding about the various imaging modalities that are used to perform IR procedures. They also lacked knowledge about the use of ionizing radiation. Radiation safety for both radiology and non-radiology nurses has been well documented in previous studies. Results indicate that non-radiology nurses are not familiar with the inherent safety protocols of radiology and IR.

Non-radiology nurses consistently commented on how they lacked confidence when implementing IR preprocedural and postprocedural care. This left them feeling confused and unsure of how to safely provide care for their IR patients. Participants voiced a 
Table 1

A sample of significant excerpts, meanings, and themes

\begin{tabular}{|c|c|c|}
\hline Significant excerpts & Meanings & Themes \\
\hline $\begin{array}{l}\text { "Not been any education about IR procedures" } \\
\text { "I don't recall learning [about IR] a lot in class" } \\
\text { "In school there wasn't a whole lot of education" } \\
\text { "There isn't very much training... in the hospital" }\end{array}$ & Lack of formal education & $\begin{array}{l}\text { No formal IR education in nursing } \\
\text { curriculum }\end{array}$ \\
\hline $\begin{array}{l}\text { "Purely by experience here, I have never worked there [in IR] } \\
\text { "I see more now in emergency...so definitely have more experience" }\end{array}$ & $\begin{array}{l}\text { Learning occurs through nursing } \\
\text { experience }\end{array}$ & $\begin{array}{l}\text { Acquired knowledge through self- } \\
\text { teaching }\end{array}$ \\
\hline $\begin{array}{l}\text { "I don't think I've been prepped as a nurse too well about the procedures they do } \\
\text { in angios" } \\
\text { "I have pretty much no knowledge to what happens [in IR]" } \\
\text { "I didn't feel as confident cause I didn't know all these different procedures" }\end{array}$ & $\begin{array}{l}\text { Increasing knowledge helps build } \\
\text { confidence }\end{array}$ & $\begin{array}{l}\text { Lacked knowledge about imaging } \\
\text { modalities and IR procedures }\end{array}$ \\
\hline $\begin{array}{l}\text { "If someone is gasping for breath that is a reason for me to call...it's purely } \\
\text { advocating on their behalf" } \\
\text { "There is nothing worse than when a patient asks, and you are like 'I don't } \\
\text { know"” } \\
\text { "I don't know what to tell patients" } \\
\text { "They are scared too because they don't know what's going to happen either, so } \\
\text { they look to us" }\end{array}$ & $\begin{array}{l}\text { Lack of knowledge limits capacity to } \\
\text { advocate and provide holistic care }\end{array}$ & $\begin{array}{l}\text { IR knowledge gap prevented } \\
\text { development of a trusted nurse-patient } \\
\text { relationship }\end{array}$ \\
\hline $\begin{array}{l}\text { "You have the pre-checked order set of what you need to do" } \\
\text { "We won't be notified that it has or hasn't been done" } \\
\text { "It would be more helpful to know what they have done more in-depth" } \\
\text { "I felt like the person there didn't tell me anything that I needed to know but } \\
\text { then I saw on my floor that my charge nurse was knowledgeable" } \\
\text { "If we had any other procedure done there would be post-op orders, so they } \\
\text { have to be there after any angio procedure, on every patient that comes, and } \\
\text { we don't always get that." }\end{array}$ & $\begin{array}{l}\text { Breakdowns with verbal and written } \\
\text { communication }\end{array}$ & $\begin{array}{l}\text { Incomplete handoffs and ineffective } \\
\text { communication disrupted continuity of } \\
\text { care }\end{array}$ \\
\hline
\end{tabular}

IR = interventional radiology.

strong desire to have current, written resources that provide clear direction and instruction particularly relating to preprocedural care.

The whole preprocedure on what the expectation is for us and what we need to get the patient ready is confusing, unless you have had a lot of experience with different procedures and patients and you have been here for a long time (participant 8).

I didn't know all these different procedures and all these drains, so a little seminar beforehand would have been helpful just to boost my confidence (participant 1 ).

I have a very rudimentary understanding of what those procedures are...what is running through my mind is what kind of assessments do I need to do... having more knowledge about the procedure means that you can better understand to watch for complications (participant 6).

\section{IR Knowledge Gap Prevented Development of a Trusted Nurse- Patient Relationship}

Non-radiology nurses expressed difficulty building a trusting nurse-patient relationship with IR patients. Without knowing what happens to patients in the IR department, they could not explain procedures to patients and families. They felt this lack of knowledge decreased patients' trust in their abilities, limited their capacity to provide holistic care, and diminished their efforts to advocate for patients.

Holistic nursing involves alleviating patients' anxiety and providing emotional support. One nurse commented on the challenge of building a trusting relationship when "I really don't know much about it because I never worked in an area like that before." She felt unable to provide holistic care to her anxious patients because she did not know exactly "what is going to happen other than the nurse down there will care for you" (participant 7). Similarly, another nurse expressed frustration with not knowing what to tell patients and having to defer their questions until the patient could speak with staff who work in the IR department.
Furthermore, not knowing what was going on in the IR department prevented this participant from advocating for a patient. "It was delays in getting a procedure done and the patient suffering...the patient was brought right down to the doors of IR and turned back because something else was happening" (participant 2). Likewise, most participants described not knowing when their patients' procedures were going to happen. "It might be a week or longer for patients to get their procedures so that affects us and our patient care... we are all connected" (participant 7). Having to witness their patients' ongoing distress when delays in treatment occurred was difficult and led to feelings of stress and frustration.

\section{Incomplete Handoffs and Ineffective Communication Disrupted Continuity of Care}

Non-radiology nurses are responsible for the handoff and safe transition of patients between inpatient wards and IR departments. Continuity of care occurs through verbal and written reports. All of the non-radiology nurses in this study raised the point that continuity of care was disrupted because of breakdowns in verbal and written communication. Several participants echoed similar thoughts to this participant's description of limited communication about what happened in an IR procedure during handoff.

I think the information is limited when I go to pick up the patient because I don't have the knowledge base to begin with. I may know if they weren't able to stent the patient because the artery is too blocked, but it is basic. Most of the information I'm getting is just on the recovery phase... as opposed to the details of what really happened during the procedure (participant 8 ).

According to participants, information shared verbally between the sending and receiving nurses varied. One participant described feeling more comfortable to ask specifics about the procedure if they knew the IR nurse personally. Another talked about how she felt the IR team made assumptions and had expectations that "you should know what they are talking about, but you don't necessarily" (participant 9). Without in-depth knowledge of what occurred 
during the procedure, non-radiology nurses were not able to focus their assessments to provide postprocedural care, observe for complications, achieve positive patient outcomes, and provide their patients with accurate information.

Breakdown in written communications also disrupted continuity of care. Non-radiology nurses in this study expected a written report of physician's orders that must be completed when receiving patients from IR departments. Participants voiced their frustration when these were not available. One nurse discussed an incident where she took time away from patient care to make repeated calls to obtain missed reports.

\section{Discussion}

The key findings of this study are that non-radiology nurses have no formal IR education in their nursing curriculum, acquire knowledge through self-teaching, lack knowledge about imaging modalities and IR procedures, are impeded to build trusting nursepatient relationships, and felt breakdown in communications disrupted the continuity of care they provided. These findings reflect pressing professional development needs. In response, we discuss how creating IR nursing specialty education, increasing awareness of the specialty of IR nursing, and enhancing clinical collaboration can begin to support non-radiology nurses toward providing safer care.

\section{Create IR nursing specialty education}

IR is leading edge for technologically advanced minimally invasive procedures. Non-radiology nurses provide around-theclock care for patients undergoing these procedures, including preprocedure and postprocedure care. However, unless their professional development need for more specialty education is met, they will continue to simply learn and improve their practice by trial and error. Nurses should not feel as though the only learning resource available to them is chance encounters with more experienced nurses. They should not practice with such a limited level of knowledge that they feel unable to build trusting relationships with patients and to safely provide optimal care.

Ideally, undergraduate nursing programs would include IR specialty education in their curriculum. An IR nursing curriculum could include content about the technical use of the various imaging modalities, such as differentiating among CT scan, fluoroscopy, and ultrasound including their procedural significance and respective safety measures. A detailed understanding of the various procedures performed in IR includes the anatomy, pathophysiology, and clinical indications for each with opportunities to observe procedures during clinical placement. Relevant content could also include information about the use of procedural sedation, education about the preprocedural, intraprocedural, and postprocedural assessments including rationale for laboratory tests, allergy identification, and comorbidities, common medications, and sepsis training. Additional content including discharge teaching about managing and troubleshooting equipment as well as how to handle potential complications to decrease emergency visits and readmissions to the hospital after discharge could be incorporated. We support existing literature that identifies a significant need for increasing curricula related to IR (Farrell \& Halligan, 2017; Mustonen, 2016; Penzias, Cadman, Sullivan \& McIntosh, 2015; Powell, 2007; Sousa, 2011). When this is not feasible, opportunities such as online learning modules provided by educational institutions and IR specialty organizations could begin to address this critical need for IR specialty education.

IR specialty education could also be delivered through inhospital orientation sessions. This would be a valuable professional development opportunity where non-radiology nurses could increase their knowledge about the specific procedures that are performed in their individual IR facilities. In addition, written guidelines reflecting best practice that describe specific hospital policies and procedures related to pre- and post-IR procedural nursing care; how nurses could best implement standards of care; and how they could access personnel with IR specialty experience would also support the professional development of these nurses. Although information explaining orientation to IR departments is available, the literature is silent on programs geared to non-radiology nurses working in hospitals (Cefaratti, Benninger \& Nguyen, 2013; Clark \& McClain, 2004; Gill \& Shanta, 2019; Jeffery \& Werthman, 2015; Penzias et al., 2015; Sousa, 2011; Vlach, 2018).

\section{Increase awareness of the specialty of IR nursing}

A "mystery," an "unknown entity," and "unfamiliar territory" are terms non-radiology nurses, community nurses, and other authors have used to describe the specialty of IR (Farrell \& Halligan, 2017; Kelly, 2013; Potter, 2015; Powell, 2007). The accredited certified radiology nurse $(C R N \otimes)$ program recognizes nurses for achieving indepth knowledge and a standard of competency in the specialty of radiology (Radiologic Nursing Certification Board, 2020). There are few nurses in Canada who possess this designation, which supports the need for increased awareness about this specialty area of nursing.

The non-radiology nurses in this study reported either limited or no physical contact with $\mathrm{CRN} \circledast$ or IR staff. Lack of IR nursing exposure extends from in-hospital and community to a broader invisibility through Canadian provincial and national nursing associations.

The participants agreed that the specialty of IR nursing and the skills required to care for this client population need to extend beyond the doors of the IR department throughout the entire hospital. Increased exposure and awareness of all the IR procedures performed, where they are performed, the imaging modality that is used to perform them, what they involve before, during, and after the procedure, and the process of how the IR procedures are scheduled is important professional development knowledge that non-radiology nurses need.

\section{Enhance clinical collaboration}

Collaboration between non-radiology nurses working with inpatients on hospital wards and IR departments is essential. Nonradiology nurses cannot provide safe patient care without collaboration to increase their understanding of the IR procedures performed. When nurses do not understand the procedures patients have undergone, they simply engage in postprocedural tasks rather than implementing informed nursing assessments. As McClaran and Scarbrough (2015) asserted, hospital nurses' lack of IR knowledge directly contributes to patients' postprocedural complications. Non-radiology nurses need clear written explanations of procedures their patients have undergone and specific instructions and resources for providing nursing care.

Without collaboration to notify nurses of schedule changes (such as accommodating a high need patient), nurses cannot advocate for those patients who must subsequently endure a long and uncomfortable wait. Having notification processes in place could decrease the nurses' feelings of stress and enhance clinical collaboration.

Collaboration is needed between interventional radiologists and non-radiology nurses as well. Interventional radiologists in Canada perform procedures primarily through a referral service. The degree of clinical involvement with patients vary depending on IR personnel and hospital supports, such as an interventional radiologist having admission privileges. Zener et al. (2018) note that only 46\% of 
interventional radiologists working in Canada have admitting privileges. This can lead to the continuity of patient care being compromised when interventional radiologists do not oversee the clinical management of their patients. Non-radiology nurses in this study stated that they did not initially think to notify the interventional radiologist about patient concerns relating to an IR procedure instead notified the most responsible physician. This lack of collaboration creates a breakdown in communication that can result in miscommunication or information not being communicated at all. As a consequence, patients are not prepared for their procedures, they may experience complications, treatment for complications may be delayed and the efficiencies of the IR department are compromised. Clinical collaboration could be enhanced by identifying either the interventional radiologist's name and contact number on patients' charts or a clinical liaison.

Finally, collaboration is needed between hospital and community nurses when patients are discharged. Community nurses' lack of education and knowledge about percutaneous drains inserted in an IR department relied on hospital nurses to inform them about IR procedures and required nursing care (Farrell \& Halligan, 2017). Lack of collaboration can result in setbacks for patients. Once again, written resources explaining IR procedures and required nursing care would enhance clinical collaboration.

Advanced nurse practice roles rooted in the nursing model, such as clinical nurse specialists (CNSs), have recently been introduced into IR to enhance clinical collaboration, provide IR specialty expertise, consult about care needs before and after procedures, and coach, educate, and incorporate new and existing research (Muehlbauer, 2011; Penzias et al., 2015). CNSs in IR serve as an essential multidisciplinary and interprofessional liaison with the rest of the hospital and have the potential to enhance efficiency, alleviate confusion, and improve communication for patients and team members.

\section{Limitations}

The limitations of this study include the sole use of interviews for data collection restricting triangulation of data sources and a small, nondiverse sample with low-inference analysis inhibiting the generalization of the findings.

\section{Future development}

Further research exploring non-radiology nurses' experiences using a larger, more diverse sample within an urban, academic setting, investigating discharge planning practices specific to IR procedures, and examining how the role of an advanced nurse practitioner (APN) influences patient safety and the efficiencies of an IR department is needed.

\section{Conclusion}

IR is a specialty that will continue expanding with the development and application of advanced technology and an ongoing valuing of minimally invasive procedures. This research provided non-radiology nurses with the opportunity to express, in their own words, their experiences caring for hospitalized IR patients. As a result, we now have a deeper understanding of the professional development needs of this group of nurses.

As non-radiology nurses strive to provide safe and informed preprocedure and postprocedure care to their IR patients, they do so with few available resources. Gaps in their undergraduate nursing curriculum did not equip them for IR practice. Once in practice, they acquired their knowledge mainly through selfteaching and frequently relied on informal exchanges of information with more experienced nurses. Addressing non-radiology nurses' professional development needs centers on providing them with the information they need to care for IR patients. We recommend beginning this process by creating opportunities for IR education. Educational institutions and professional associations are well positioned to host learning modules and they can be accessed by both preservice and in-service learners. In-hospital orientation sessions are also a practical venue for IR education.

In addition, we recommend increasing awareness of the specialty of IR nursing. When specialists in IR departments actively seek out opportunities to share information, non-radiology nurses can provide safer, more informed care in hospitals as well as community settings. Knowing that lack of collaboration among IR departments, hospital, and community nurses can impact the provision of safe holistic care, the need for professional development opportunities that enhance interdepartmental collaboration becomes clear. In sum, there is a pressing need to develop resources that non-radiology nurses can use to deepen their understanding of IR. This is both a challenge and an opportunity for the field.

\section{Acknowledgments}

The authors thank the ten participating nurses for sharing their views and experiences.

The Association for Radiologic and Imaging Nursing (ARIN) Dorothy Budnek Memorial Scholarship is acknowledged for financial assistance.

CRediT Author Statement: Andra Carley contributed to Conceptualization, Investigation, Formal analysis, Writing - Original draft, Project administration. Sherri Melrose contributed to Supervision, Writing-Reviewing and Editing. Gwen Rempel: Writing-Reviewing and Editing. William Diehl-Jones contributed to Writing-Reviewing and Editing. Betty-Anne Schwarz contributed to Writing-Reviewing and Editing.

\section{References}

Aspers, P., \& Corte, U. (2019). What is qualitative in qualitative research. Qualitative Sociology, 42, 139-160. . Accessed December 2, 2020.

Association for Radiologic and Imaging Nursing. Retrieved from https://www. arinursing.org. Accessed December 1, 2020.

Bradshaw, C., Atkinson, S., \& Doody, O. (2017). Employing a qualitative description approach in health care research. Global Qualitative Nursing Research, (4), 1-8.

Braun, V., \& Clarke, V. (2006) Using thematic analysis in psychology. Qualitative Research in Psychology, 3(2), 77-101. Retrieved from https://core.ac.uk/ download/pdf/1347976.pdf. Accessed December 1, 2020.

Canadian Association for Interventional Radiology. Retrieved from https://www. cairweb.ca/en/. Accessed December 1, 2020.

Cefaratti, M., Benninger, R., \& Nguyen, R. (2013). Implementing a hospital-based radiology nursing orientation program for new graduate pediatric nurses. Journal of Radiology Nursing, 32(4), 170-179. https://doi.org/10.1016/ j.jradnu.2013.09.001. Retrieved from . Accessed December 1, 2020.

Clark, P.L., \& McClain, I.B. (2004). Evaluative study of current orientation practices in interventional radiology nursing. Journal of Radiology Nursing, 23(1), 3-11.

Creswell, J.W., \& Poth, C.N. (2018). Qualitative inquiry and research design: Choosing among five approaches (4th ed.). Los Angeles, CA: Sage.

Farrell, R., \& Halligan, P. (2017). Nurses' experience of caring for patients in the community after discharge with an interventional radiology drain in Ireland Journal of Radiology Nursing, 26(4), 228-235. https://doi.org/10.1016/ j.jradnu.2017.08.001. Retrieved from . Accessed December 2, 2020.

Foo, M., Maingard, J., Phan, K., Lim, R., Chandra, R.R., Lee, M.J., Asadi, H., Kok, H.K., \& Brooks, M. (2018). Australian students' perspective on interventional radiology education: A prospective cross-institutional study. Journal of Medical Imaging and Radiation Oncology, 62(6), 758-763.

Gill, A.M., \& Shanta, L.L. (2019) Application of transition theory for orientation of experienced nurses to radiology and imaging nursing. Journal of Radiology Nursing. Retrieved from https://0-www-sciencedirect-com.aupac.lib.athabascau.ca/science/article/pii/S1546084319301774. Accessed December 2, 2020.

Guba, E.G., \& Lincoln, Y.S. (1994). Competing paradigms in qualitative research. In N.K. Denzin, \& Y.S. Lincoln (Eds.), Handbook of Qualitative Research (pp. 105-117). Thousand Oaks, CA: Sage Publications.

Jeffery, D.D., \& Werthman, J. (2015). Successful orientation strategies for radiology nurses. Journal of Radiology Nursing, 34(2), 94-99. 
Kelly, K. (2013) The changing image of radiology nursing. Canadian Nurse, 109(2), 26-27. Retrieved from https://www.cna-aiic.ca/en/canadian-nurse-home/ articles/issues/2013/february-2013/the-changing-image-of-radiology-nursing. Accessed December 1, 2020.

Kivunja, C., \& Kuyini, A.B. (2017) Understanding and applying research paradigms in educational contexts. International Journal of Higher Education, 6(5), 26-41. Retrieved from https://files.eric.ed..gov/fulltext/EJ1154775.pdf. Accessed December 2, 2020.

Lambert, V.A., \& Lambert, C.E. (2012). Qualitative descriptive research: An acceptable design. Pacific Rim International Journal of Nursing Research, 16(4), 255-256.

McClaran, J., \& Scarbrough, K. (2015). Root cause analysis of preventable limb loss and subsequent death after arteriogram: Improved focused nursing education and system processes. Journal of Radiology Nursing, 34(1), 39-42.

Medical Imaging Nurses Association of Australia. Retrieved from https:// minanational.org.au/. Accessed December 1, 2020.

Muehlbauer, P.M. (2011). Emerging roles in interventional radiology. ONS Connect, 26(9), 8-12.

Mustonen, R. (2016). Collaboration experience between association for radiologic and imaging nursing and nursing unit in medical imaging department, ministry of national guard health affairs, Riyadh, Saudi Arabia. Journal of Radiology Nursing, 35(1), 24-28.

Neergaard, M.A., Oleson, F., Andersen, R.S., \& Sondergaard, J. (2009). Qualitative description-the poor cousin of health research? BMC Medical Research Methodology, 9(52).

Penzias, A., Cadman, S., Sullivan, A., \& McIntosh, K. (2015). Mentoring the nurse of the future: Clinical nurse specialist students in the radiology setting. Journal of Radiology Nursing, 34(3), 150-156.
Potter, T. (2015). Partnership-imaging a new model in health care. Journal of Radiology Nursing, 34(2), 57-62.

Powell, J. (2007). An interventional radiology clinical rotation to enhance student learning. Journal of Nursing Education, 46(10), 476-479.

Radiologic Nursing Certification Board. Retrieved from https://www. certifiedradiologynurse.org/. Accessed December 4, 2020.

Richards, L., \& Morse, J.M. (2013). Readme first for a user's guide to qualitative methods (3rd ed.). Los Angeles, CA: Sage.

Sandelowski, M. (2000). Whatever happened to qualitative description? Research in Nursing \& Health, 23, 334-340.

Sandelowski, M. (2010) What's in a name? Qualitative description revisited Research in Nursing \& Health, 33(1), 77-84. Retrieved from https://0onlinelibrary-wiley-com.aupac.lib.athabascau.ca/doi/pdf/10.1002/nur.20362. Accessed December 1, 2020.

Sousa, M.F. (2011). Management and leadership: Educating and orienting the radiology nurse of the future. Journal of Radiology Nursing, 30(3), 135-136.

Vlach, R. (2018). Radiology nursing specialty orientation. Journal of Radiology Nursing, 37(2), 112-118.

Willis, D., Sullivan-Bolyai, S., Knafl, K., \& Cohen, M. (2016). Distinguishing features and similarities between descriptive phenomenological and qualitative description research. Western Journal of Nursing Research, 38(9), 1185-1204.

Zeidenberg, J. (2007) Report on interventional radiology. Retrieved from https:// www.legerradiologie.qc.ca/images/pdf/ReportInterventionalRadiology.pdf. Accessed December 4, 2020.

Zener, R., Demers, V., Bilodeau, A., Benko, A., Abraham, R., Wong, J., \& Kachura, J. (2018). Clinical IR in Canada: The evolution of a revolution. Journal of Vascular and Interventional Radiology, 29(4), 524-530. 